\title{
Article \\ A Study of the Effects of Geosynthetic Reinforced Soil and Reinforcement Length on GRS Bridge Abutment
}

\author{
Myoung-Soo Won (1) and Christine Patinga Langcuyan * \\ Department of Civil Engineering, Kunsan National University, 558 Daehakro, Gunsan 54150, Korea; \\ wondain@kunsan.ac.kr \\ * Correspondence: cplangcuyan@kunsan.ac.kr
}

Citation: Won, M.-S.; Langcuyan, C.P. A Study of the Effects of Geosynthetic Reinforced Soil and Reinforcement Length on GRS Bridge Abutment. Appl. Sci. 2021, 11, 11226. https://doi.org/10.3390/ app112311226

Academic Editors: Xiaowu Tang and Chao Xu

Received: 30 October 2021

Accepted: 24 November 2021

Published: 26 November 2021

Publisher's Note: MDPI stays neutral with regard to jurisdictional claims in published maps and institutional affiliations.

Copyright: () 2021 by the authors. Licensee MDPI, Basel, Switzerland. This article is an open access article distributed under the terms and conditions of the Creative Commons Attribution (CC BY) license (https:// creativecommons.org/licenses/by/ $4.0 /)$.

\begin{abstract}
The geosynthetic reinforced soil (GRS) bridge abutment with a staged-construction full height rigid (FHR) facing and an integral bridge (IB) system was developed in Japan in the 2000s. This technology offers several advantages, especially concerning the deformation behavior of the GRS-IB abutment. In this study, the effects of GRS in the bridge abutment with FHR facing and the effects of geosynthetics reinforcement length on the deformation behavior of the GRS-IB are presented. The numerical models are analyzed using the finite element method (FEM) in Plaxis 2D program. The results showed that the GRS-IB model exhibited the least lateral displacements at the wall facing compared to those of the IB model without geosynthetics reinforcement. The geosynthetics reinforcement in the bridge abutment with FHR facing has reduced the vertical displacement increments by 4.7 times and 1.3 times (maximum) after the applied general traffic loads and railway loads, respectively. In addition, the numerical results showed that the increase in the length-to-height $(\mathrm{L} / \mathrm{H})$ ratio of reinforcement from $0.3 \mathrm{H}$ to $1.1 \mathrm{H}$ decreases the maximum lateral displacements by $29 \%$ and the maximum vertical displacements by $3 \%$ at the wall facing by the end of construction. The effect of the reinforcement length on the wall vertical displacements is minimal compared to the effect on the wall lateral displacements.
\end{abstract}

Keywords: geosynthetics; geosynthetic reinforced soil (GRS); integrated bridge system (IBS); reinforcement length; numerical modeling; bridge abutment

\section{Introduction}

One of the remarkable developments in geosynthetic reinforced soil (GRS) technology is the geosynthetic-reinforced soil integrated bridge system (GRS-IBS). The GRS-IBS was initially developed by the Federal Highway Administration (FHWA) in the United States and now has several variations. One of those variations was developed in Japan using a GRS retaining wall (RW) as bridge abutment with a staged-construction full height rigid (FHR) facing and an integral bridge system (IBS). This GRS RW with stage-construction FHR facing was first implemented in the mid-1980s and developed in the 2000s as a bridge abutment, integrating a continuous reinforced concrete $(\mathrm{RC})$ girder on top of the FHR facing without the use of bearings. The GRS integral bridge (GRS-IB) technology alleviates the technical difficulties of conventional bridges by solving problems related to RC structures by eliminating the bearings and joints. It has also solved several problems involving backfill using geosynthetics reinforcement. Moreover, the GRS-IB technology has been proven highly cost-effective in construction and long-term maintenance while remaining stable under static and seismic loading conditions [1-4].

Geosynthetics (geotextile) have been used as reinforcement since the early 1970s. One of the first geotextile reinforced walls in the United States was built in Siskiyou National Forest, Oregon. In 1971, the first geotextile-reinforced soil was constructed in France for improving embankment stability. A similar structure was constructed in the United States in 1974. Around the early 1980s, geogrids were developed and used as soil reinforcements. 
In 1981, the first geogrids-reinforced soil was used. The extensive use in the United States began around 1983 [5-10]. The technology has been widely used as temporary support on permanent roadway embankments. Since then, there has been a significant increase in the application of geosynthetics reinforced soil. The use of geosynthetics as reinforcement improves the mechanical properties of the soil by providing tensile strength lacking in soil and rigidity against shear and bending forces. Geosynthetic reinforcement increases the bearing capacity of the soil and restrains the deformation in soil subjected to external forces. The common applications of geosynthetics in geotechnical engineering can be found in the improvement and stabilization of soft or weak grounds, slopes, embankments, and retaining walls [7,11-14]. Some successful applications of geosynthetics also include the protection of buried pipes $[15,16]$. Geosynthetics reinforcement is a growing field, and its continued development remains a high priority for many private and government institutions worldwide.

\section{Need for Research}

This study presents the GRS bridge abutment with FHR facing in stage-construction, integrated continuously with the RC girder, or the so-called GRS-IB. The research focused on two main objectives: first, to study the effects of geosynthetic reinforcement of the bridge abutment, specifically with FHR facing in staged construction, and second, to examine the effects of geosynthetics reinforcement length on the deformation behavior of the GRS-IB abutment. A series of numerical analyses were undertaken using the finite element method (FEM) in Plaxis 2D program. The details of the numerical modeling are discussed in the following section of the paper, together with the results from the numerical simulations and comparisons of the GRS-IB abutment behavior presented in graphs.

\section{Numerical Modeling \\ 3.1. Model Description}

In this study, the integrated bridge with GRS abutment and FHR facing in stagedconstruction (GRS-IB) is modeled and analyzed using Plaxis 2D AE.02 Version 2013 program. The design details of the GRS-IB model are taken from the Won and Langcuyan [17]. The GRS-IB model includes a GRS abutment, reinforced soil foundation (RSF), FHR facing, and RC footing. The FHR facing is the substructure that is continuously connected to the superstructure of the $\mathrm{RC}$ bridge girder, eliminating the joints and bearings, thus forming an integral bridge structure. The FHR facing has a width of $0.9 \mathrm{~m}$, a footing width of $1.35 \mathrm{~m}$, and a thickness of $0.9 \mathrm{~m}$. The RSF extends by $1.0 \mathrm{~m}$ from the toe of the FHR footing. The abutment has a cut slope of 1:1. The bridge loads are supported directly by the FHR facing. The FHR facing is connected to the GRS RW abutment. The abutment uses gravel bags placed at the facing, compacted to a thickness of $0.1 \mathrm{~m}$ and a width of $0.4 \mathrm{~m}$. Similar to the reference studies, only the right-hand side of the bridge and abutment is considered. This method of modeling the free-standing geometry of the GRS bridge abutment was also used by Abu-Farsakh et al. [18,19], Ardah et al. [20,21], Won and Langcuyan [17], and Zheng and Fox [22]. The integrated approach backfill and the RC bridge girder are removed and converted into their equivalent vertical loads. Thus, the height $(\mathrm{H})$ of the abutment was left at $6.3 \mathrm{~m}$ from the base of the wall. As a result, the right-hand side of the GRS-IB model (referred to as Case 1 throughout this paper) is shown in Figure 1a, and its corresponding numerical model using Plaxis 2D is shown in Figure $1 \mathrm{~b}$.

In addition, the conventional integral bridge (IB) model is included in the study to show the effects of having an IB system without the geosynthetics reinforcement in the abutment. The configuration of the IB model is based on the GRS-IB model, which includes RSF, FHR facing, and RC footing. The design details of the IB model are also taken from the Won and Langcuyan [17]. Similar to the GRS-IB model, the IB model has a precise span length of $15.0 \mathrm{~m}$ and a clear height of $5.3 \mathrm{~m}$. Here, the FHR facing has a width of $0.9 \mathrm{~m}$, a footing width of $4.85 \mathrm{~m}$, and a thickness of $0.9 \mathrm{~m}$. In this design, the RSF extends $1.0 \mathrm{~m}$ from the toe of the FHR footing and $1.0 \mathrm{~m}$ from the heel of the FHR footing. The 
FHR footing is wider than the GRS-IB model because the IB model has no GRS abutment. Similarly, the right-hand side of the IB (referred to as Case 2) model is shown in Figure 2a, and its corresponding numerical model using Plaxis 2D is shown in Figure $2 \mathrm{~b}$.

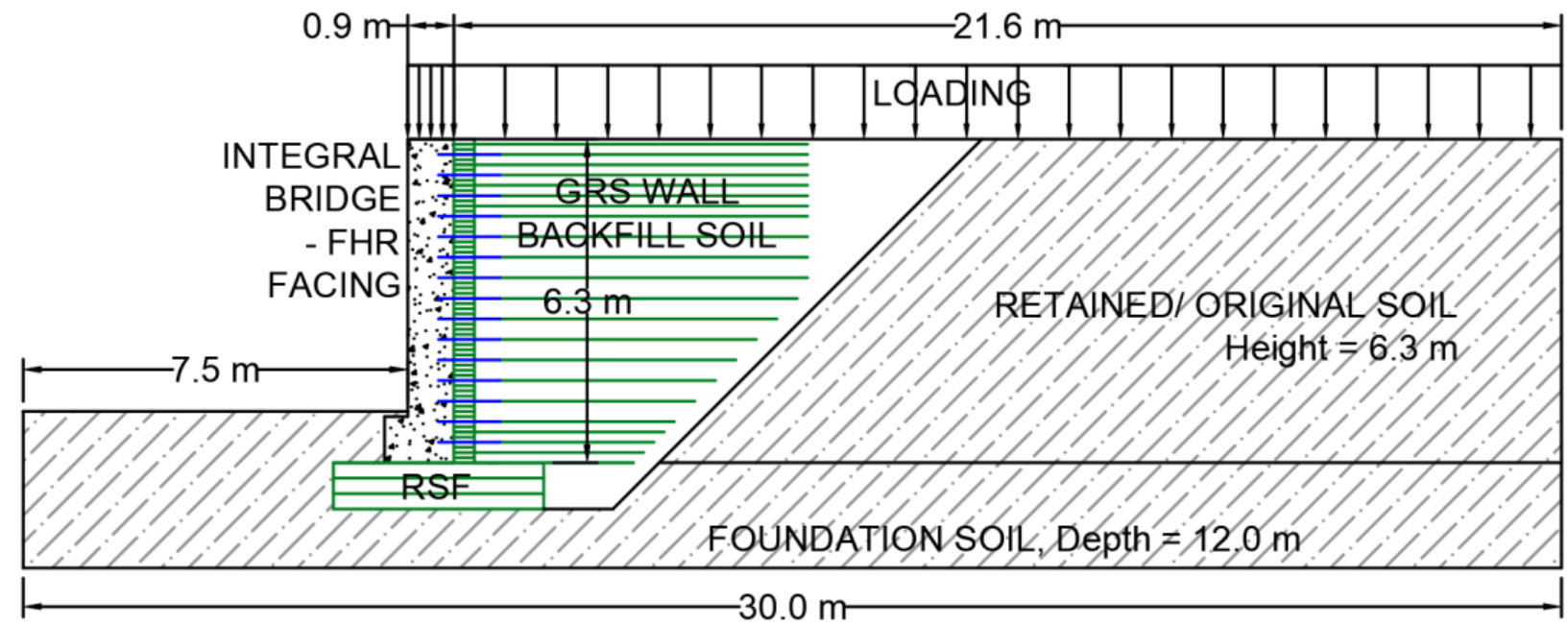

(a)

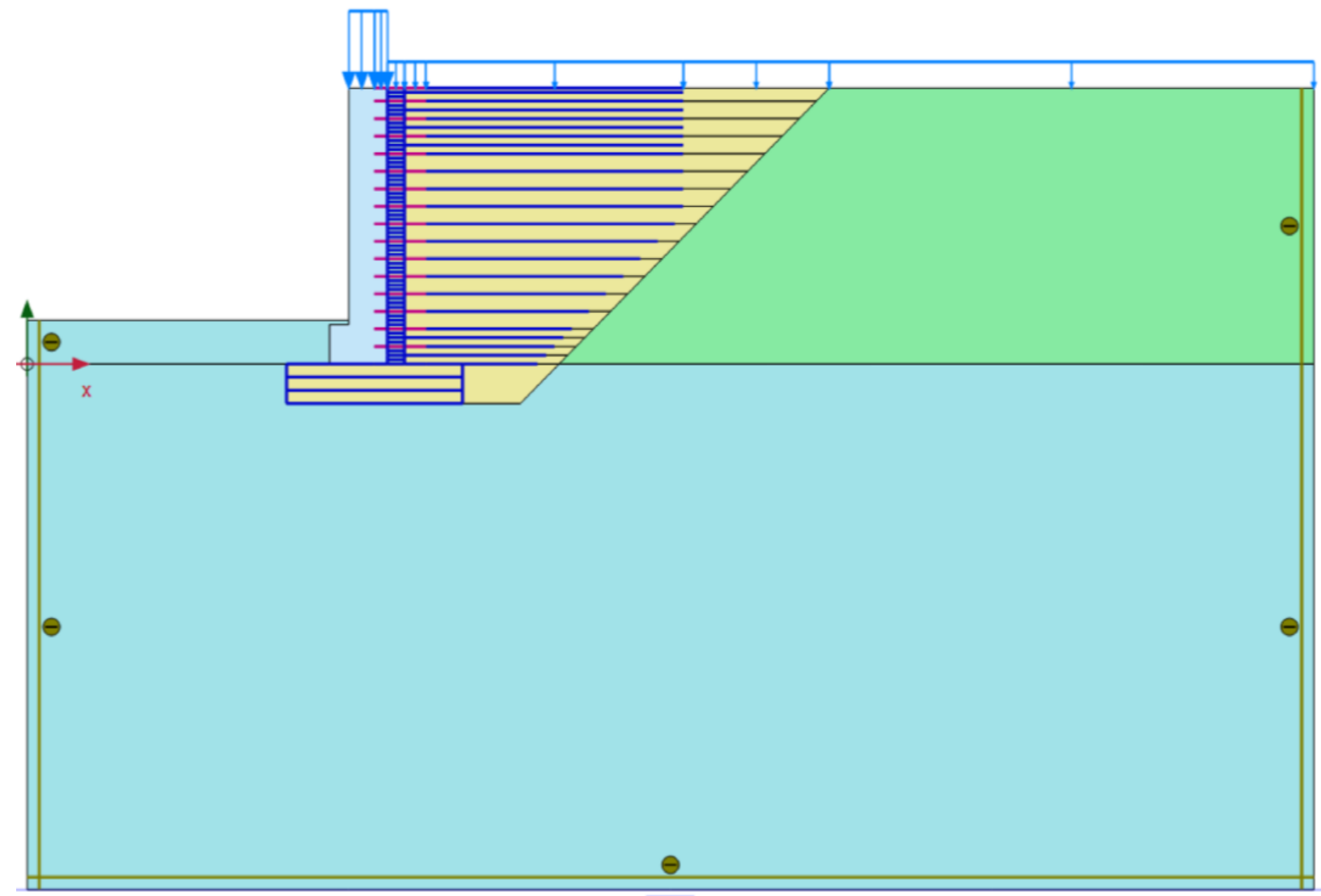

(b)

Figure 1. Design and Plaxis 2D Numerical Model for GRS-IB (Case 1). (a) Model Design for GRS-IB. (b) Plaxis 2D Numerical Model for GRS-IB. 


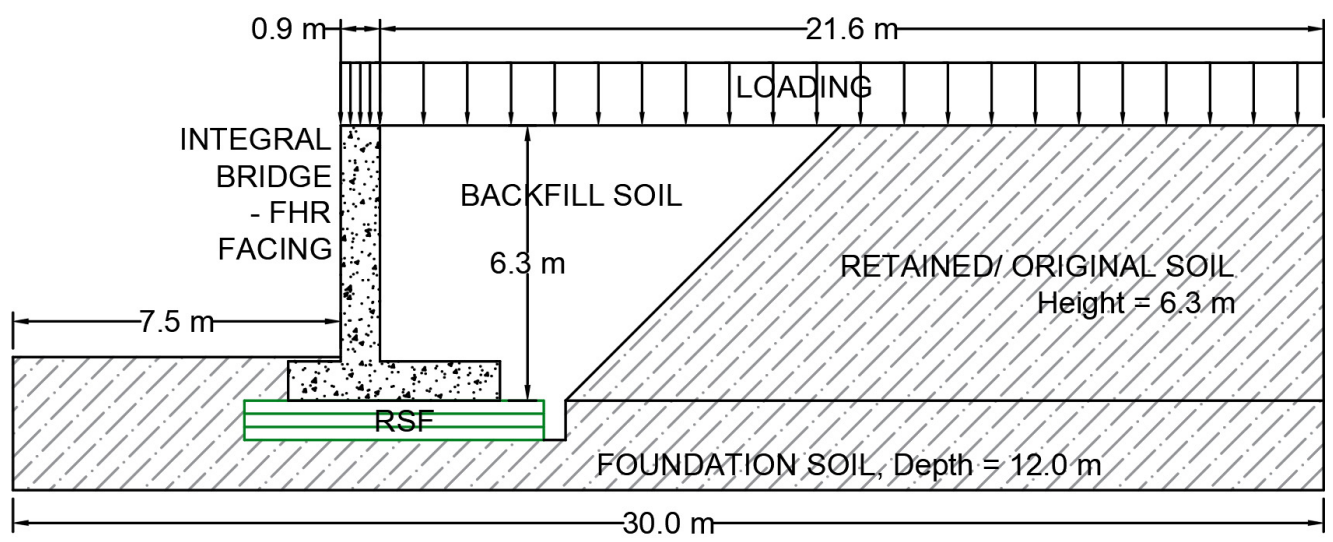

(a)

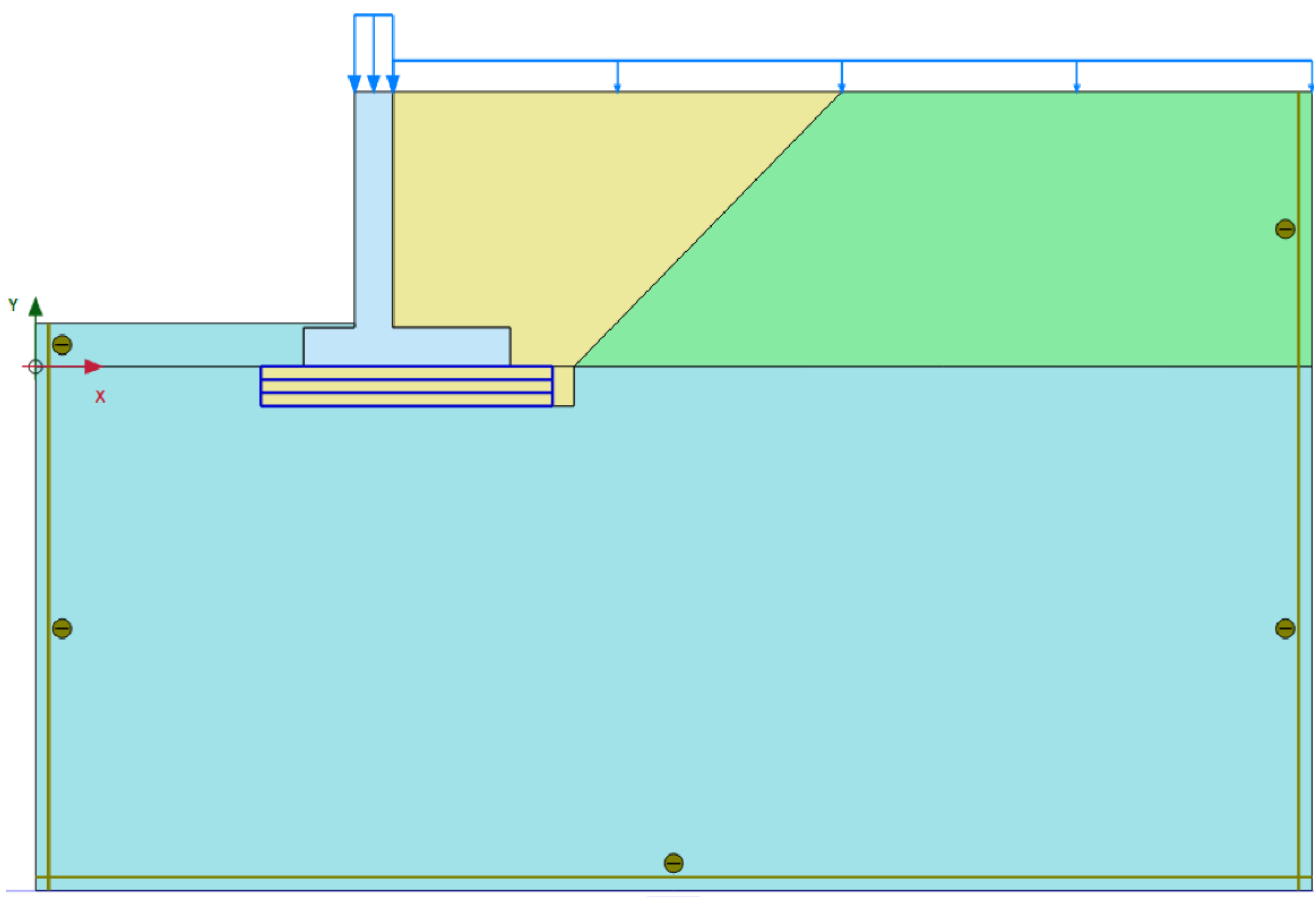

(b)

Figure 2. Design and Plaxis 2D Numerical Model for IB (Case 2). (a) Model Design for IB. (b) Plaxis 2D Numerical Model for IB.

The numerical models are designed with sufficient horizontal and vertical distance from the right end and bottom boundaries, respectively. The horizontal distance from the right end to the wall facing is more than three times the height of the wall. The vertical distance from the base of the wall to the bottom boundary is almost twice the height of the wall. The front boundary is $7.5 \mathrm{~m}$ from the wall facing, which is equivalent to half of the bridge, whose clear width is $15 \mathrm{~m}$. Consequently, the boundary conditions are modeled where the vertical sides of the models at $X=0$ and $X=30$ are fixed on $\mathrm{X}$-direction. The bottom boundary at $\mathrm{Y}=-12$ is fixed on both $\mathrm{X}$ - and $\mathrm{Y}$-direction. In other words, a fixed boundary condition is applied at the bottom of the model, while a roller boundary condition is applied on both vertical sides of the model. The FEM models of the bridge abutment are simulated in Plaxis 2D based on the example procedures in Plaxis 2D Reference and Tutorial Manuals $[23,24]$ and related literature, including Abu-Farsakh et al. [18,19], Ardah et al. [20,21], Koda et al. [25], Tatsuoka et al. [4], Won and Langcuyan [17], and Yazaki et al. [26]. The models use a plane strain condition with 15-noded triangular elements, which are the default setting in Plaxis 2D. After mesh 
generation, the Case 1 numerical model has a total of 49,687 nodes and 5441 soil elements with an average element size of $0.3176 \mathrm{~m}$. Case 2 numerical model (IB) has a total of 32,762 nodes and 3915 soil elements with an average element size of $0.3745 \mathrm{~m}$. The number of nodes and elements differs from every numerical model because the mesh depends on the geometry of the numerical model.

\subsection{Material Parameters}

\subsubsection{Soil Material Input Parameters}

The properties of the soil materials used in this study are summarized in Table 1 . The soil backfill is a gravelly material. The constitutive model used to simulate the behavior of the soil backfill is the hardening soil (HS). The HS model is an advanced model for the simulation of soil behavior. It is an elastoplastic hyperbolic model that accounts for stressdependency of stiffness moduli, which results in an appropriate behavior of the granular soil during the loading stage. In the HS model, the soil stiffness is defined more accurately by using three different parameters: (1) secant stiffness in standard drained triaxial test $\mathrm{E}_{50}^{\text {ref }}$, (2) tangent stiffness for primary oedometer loading $\mathrm{E}_{\text {oed }}^{\text {ref }}$, and (3) unloading and reloading stiffness, $E_{u r}^{\text {ref }}$, which is by default equal to $3 \times E_{50}^{\text {ref }}[23,24]$. Several related studies have also used the HS model to simulate the backfill soil, including Abu-Farsakh et al. [18], Ardah et al. [20,21], and Damians et al. [27,28]. In this study, the parameters used for the backfill soil were taken from Ardah et al. [20] and Won and Langcuyan [17].

Table 1. Material Parameters for the Soil and FHR Facing.

\begin{tabular}{|c|c|c|c|c|c|c|}
\hline Parameters & Unit & Backfill Soil & Gravel Bags & Retained Soil & Foundation & FHR \\
\hline $\begin{array}{c}\text { Material } \\
\text { Model }\end{array}$ & - & HS & HS & LE & LE & LE \\
\hline Unit weight, $\gamma$ & $\mathrm{kN} / \mathrm{m}^{3}$ & 19 & 19 & 20 & 20 & 24 \\
\hline $\mathrm{E}_{50}$ ref & $\mathrm{kN} / \mathrm{m}^{2}$ & $34.0 \times 10^{3}$ & $34.0 \times 10^{3}$ & - & - & - \\
\hline $\mathrm{E}_{\text {oed }}$ ref & $\mathrm{kN} / \mathrm{m}^{2}$ & $25.1 \times 10^{3}$ & $25.1 \times 10^{3}$ & - & - & - \\
\hline $\mathrm{E}_{\mathrm{ur}}$ ref & $\mathrm{kN} / \mathrm{m}^{2}$ & $103.2 \times 10^{3}$ & $103.2 \times 10^{3}$ & - & - & - \\
\hline $\mathrm{E}$ & $\mathrm{kN} / \mathrm{m}^{2}$ & - & - & $120 \times 10^{3}$ & $120 \times 10^{3}$ & $30 \times 10^{6}$ \\
\hline$c_{\text {ref }}$ & $\mathrm{kN} / \mathrm{m}^{2}$ & 20 & 20 & - & - & - \\
\hline$\phi(\mathrm{phi})$ & $\circ$ & 51 & 51 & - & - & - \\
\hline$\psi(p s i)$ & $\circ$ & 21 & 21 & - & - & - \\
\hline$v(\mathrm{nu})$ & - & 0.2 & 0.2 & 0.2 & 0.2 & 0.15 \\
\hline $\mathrm{R}_{\text {inter }}$ & - & 0.55 & 0.55 & 1 & 1 & 1 \\
\hline $\mathrm{K}_{0, \mathrm{x}}$ & - & 0.5 & 0.5 & 0.5 & 1 & 1 \\
\hline
\end{tabular}

The granular soil inside the gravel bags is assumed to have the same parameters as the adjacent backfill soil to avoid the complexity of the results. Since both materials are compacted and placed in a similar manner, the parameters are reasonably expected to be similar. The soil foundation and the retained original soil are modeled using linear elastic (LE). Both are assumed to have stiff properties to eliminate the influence of foundation deformation on the behavior of the bridge models. In addition, the influence of the pore water pressure was not considered in the analysis. Thus, all soil materials are modeled with drained properties. Literature reveals that the shear strength of the actual soil-structure interface is generally less than the surrounding soil [23,27-30]. Studies conducted by $\mathrm{Yu}$ and Bathurst [31] and Yu et al. [32] on geogrids reinforcements were able to replicate the experiment's results using a strength reduction factor of 0.67 . In this study, the interface coefficient at the backfill soil and reinforcements, as well as the wall facing elements, is computed as $R_{\text {inter }}=\tan \delta / \tan \varphi[28,33]$, where $\delta=2 / 3 \cdot \varphi$ and $\varphi$ are the friction angle of the soil material. The interface coefficient $R_{\text {inter }}$ for soil foundation and the retained original soil are assumed rigid and are assigned with a value of 1 (see Table 1). 


\subsubsection{Wall Facing Material Input Parameters}

The wall material used in this study is the FHR facing and is modeled as linear elastic (LE) with a nonporous drainage type. The FHR facing is made of high-strength concrete mix with unit weight $(\gamma)$ of $24 \mathrm{kN} / \mathrm{m}^{3}$ and elastic modulus (E) equal to $30 \mathrm{GPa}$. The wall-facing material is assumed rigid and was assigned a value of 1 (see Table 1).

\subsubsection{Reinforcements Material Input Parameters}

The geosynthetics reinforcements used for the RSF, GRS wall, and integrated approach are modeled as geogrids in the Plaxis $2 \mathrm{D}$ program with elastic property and axial stiffness (EA) of $1600 \mathrm{kN} / \mathrm{m}$. The EA of the geotextile was approximated to be the tensile strength $(\mathrm{T}=80 \mathrm{kN} / \mathrm{m})$ divided by the average width of elongation at $5 \%$. The steel reinforcements are added to connect the GRS RW and FHR facing with a vertical spacing of $0.4 \mathrm{~m}$ and horizontal spacing of $0.15 \mathrm{~m}$. The steel reinforcements are modeled as a geogrids element with elastic property and EA of $2300 \mathrm{kN} / \mathrm{m}$. The EA is computed as the product of the elastic modulus of steel $(\mathrm{E}=200 \mathrm{GPa})$ and the cross-sectional area having a diameter of $13 \mathrm{~mm}$.

\subsection{Static Loading Conditions}

In this study, the bridge numerical models are subjected to three different static loadings. The static loading condition is a simple condition wherein the vertical load (dead load, live load) is assumed stationary and applied uniformly on top of the bridge and abutment. Case A loading considers the equivalent bridge girder total dead loads (167 kPa) and the approach backfill total dead loads $(18 \mathrm{kPa})$ at the end of bridge construction. Case $\mathrm{B}$ loading considers the presence of the general traffic loads after the bridge construction. The general traffic loadings are equal to the live loads of typical vehicles and trucks in addition to the bridge girder and approach backfill total dead loads. The bridge's total dead load, including general traffic live load, is $217 \mathrm{kPa}$, and the approach backfill total dead load, including general traffic live load, is $30 \mathrm{kPa}$. Lastly, Case $\mathrm{C}$ loading considers the presence of the railway loads after the bridge construction. The railway loadings are equal to the rail track total dead loads and train live loads, in addition to the bridge girder and approach backfill total dead loads. The bridge's total dead load, including rail track total dead load and train live load, is $250 \mathrm{kPa}$ and the approach backfill total dead load, including rail track total dead load and train live load, is $68 \mathrm{kPa}$ [17]. For the calculation of static loadings, Plastic calculation type and Elastoplastic drained analysis are used wherein soil consolidation was not considered. Hence, the time of construction does not have substantial effects on the behavior of the numerical models. During phase construction, the pressure from the previous phase is carried until the completion of the structure.

\section{Effects of Geosynthetics Reinforced Soil (GRS) Abutment}

In this study, the GRS-IB (Case 1) and IB (Case 2) models were analyzed to evaluate the effects of GRS abutment on the deformation behavior of the integral bridge. Case 1 model is the integral bridge with geosynthetic reinforced soil abutment and full height rigid facing (GRS-IB) in staged construction. Case 2 model is a typical integral bridge (IB) without soil reinforcement. There were three static loadings considered in this study: (a) the end of bridge construction, which is equal to the bridge and the roadway total dead loads (Case 1A-2A); (b) the general traffic loading, which is equal to the live loads of typical vehicle, in addition to the bridge and roadway total dead loads (Case 1B-2B); and (c) train loading, which is equal to the train and railway total dead loads and live loads in addition to the bridge and roadway total dead loads (Case $1 \mathrm{C}-2 \mathrm{C})$. The bridge and roadway approach backfill dead loads, general traffic loads, and railway loads are modeled as surcharge loads and applied uniformly on top of the models. 


\subsection{Lateral Displacements at Wall Facing}

The final wall-facing profiles of the bridge models at the end of bridge construction, after general traffic loading, and after railway loading are shown in Figure 3. The lateral displacements $(\mathrm{dx})$ at the wall facing from $0.90 \mathrm{~m}$ high above the base up to the top of the abutment have been considered to eliminate the part of the integral bridge footing. The $\mathrm{dx}$ at the wall facing on the GRS-IB (Case 1A-1C) and IB (Case 2A-2C) models are within the allowable lateral displacement of $1 \%(\mathrm{dx} / \mathrm{H})$. The results inferred that the lateral displacement behavior at wall facing was influenced by the bridge abutment construction method and the presence of geosynthetic reinforcements.

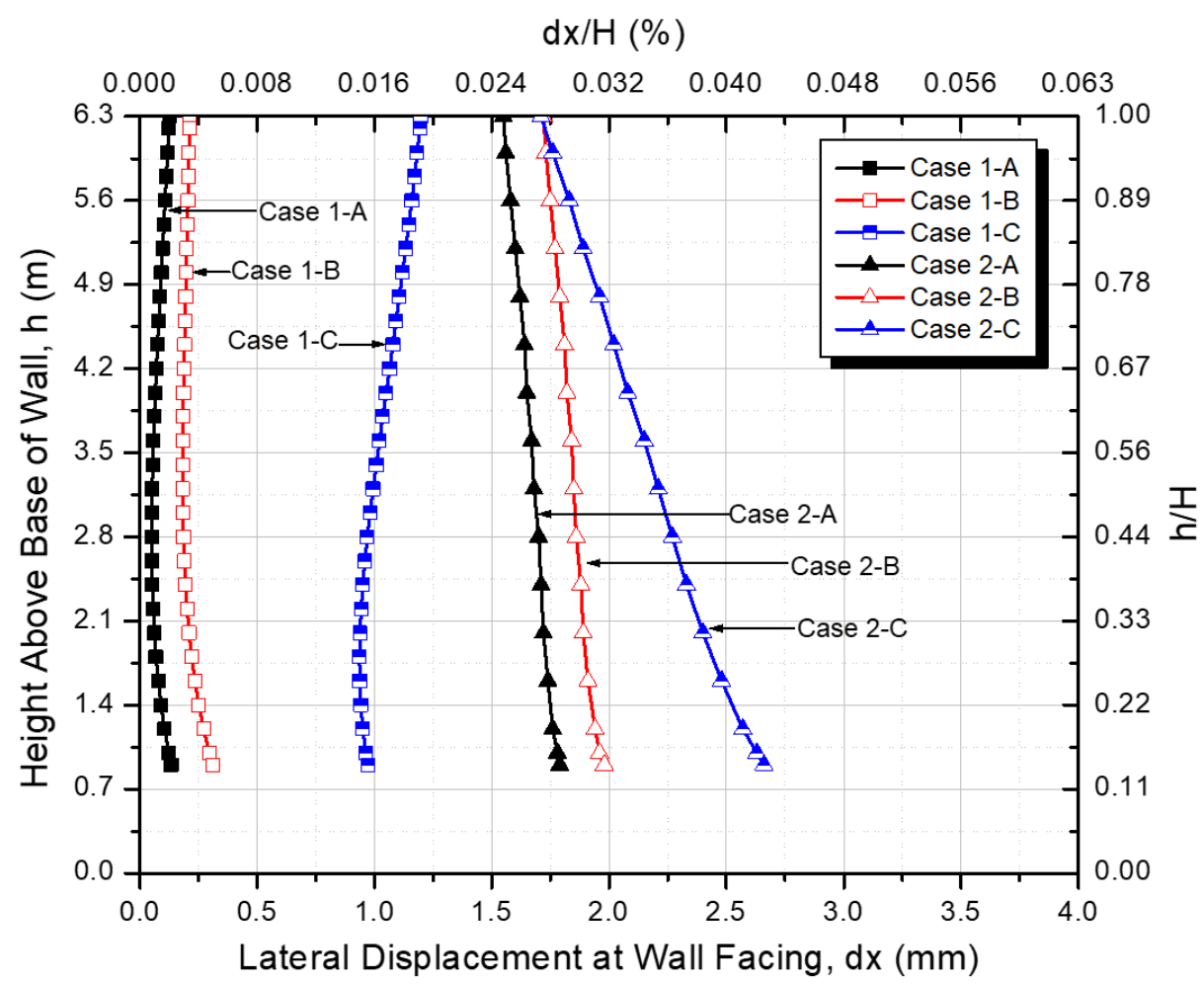

Figure 3. Lateral Displacement at Wall Facing.

The GRS-IB technology allows the $\mathrm{dx}$ at the wall facing to occur during the construction. Afterward, the GRS wall facing $\mathrm{dx}$ during the construction was eliminated when the FHR facing was constructed. The negligible $\mathrm{dx}$ at wall facing is due to the post-construction surcharge loads. This is one of the advantages of this technology wherein compaction can be applied thoroughly but cautiously on the backfill, especially near the wall facing without too much concern for the wall facing damage or excessive deformation. Moreover, the FHR facing of the GRS-IB model carries the loads from the RC girder; hence, the GRS abutment carries the minimal surcharge loads. It can be observed that the $\mathrm{dx}$ behavior of the FHR facing did not bulge but was rather almost straight from the base towards the top of the wall. This may be because the FHR facing of the GRS-IB is $0.90 \mathrm{~m}$ thick and has high stiffness. Thus, the $\mathrm{dx}$ at the wall facing in GRS-IB (Case 1A-1C) models, after the bridge construction and after load application, is minimal with a maximum range of $0.002-0.02 \%(\mathrm{dx} / \mathrm{H})$ at the top of the wall facing.

On the other hand, the IB (Case 2A-2C) model exhibited slightly greater $\mathrm{dx}$ behavior at the wall facing compared with GRS-IB (Case 1A-1C) model. The difference between the two bridge designs is that the IB model has no reinforcements in the backfill and has broader RC footing that extends behind the wall facing. The construction and type of wall facing have influenced the behavior of $d x$. During construction, the FHR facing and $\mathrm{RC}$ footing of the IB model were activated prior to the backfill lifts placement. When the FHR facing and the RC footing were constructed above the RSF, the RSF exhibited more 
displacements at the toe than at the heel, probably due to the distribution of the IB dead loads. At the end of bridge construction, it is noticeable that $\mathrm{dx}$ at wall facing is very minimal. This may be because the FHR facing of the IB model is $0.90 \mathrm{~m}$ thick and has a very high stiffness. It can be implied that the initial movement of the IB wall facing and footing at the start of construction may have significantly affected the $\mathrm{dx}$ behavior shown by the IB model.

\subsection{Vertical Displacement Increments at the Top of Wall Abutment}

The primary function of soil reinforcement is to restrain soil deformation. In this study, the effects of geosynthetics reinforcement on the vertical displacements at the top of wall abutment can be observed in Figure 4, showing the vertical displacement increments $(\Delta$ dy) obtained from the current calculation phase for (a) the applied general traffic loads (Case 1B-2B), and (b) for the applied railway loads (Case 1C-2C). In this condition, the geosynthetic reinforcements worked well in the backfill soil by resisting the $\Delta$ dy from the vertical earth pressures induced by the applied surcharge loads. The results show that the GRS-IB model with FHR facing and reinforced backfill exhibited the least vertical displacements increments $(\Delta \mathrm{dy})$ at the top of the wall abutment. In this study, both GRS-IB and IB models have the same loading conditions. Because of the presence of the reinforcements, the GRS-IB models have reduced the $\Delta$ dy by 4.7 times and 1.3 times (maximum) after the applied general traffic loads and railway loads compared to the IB models, respectively.

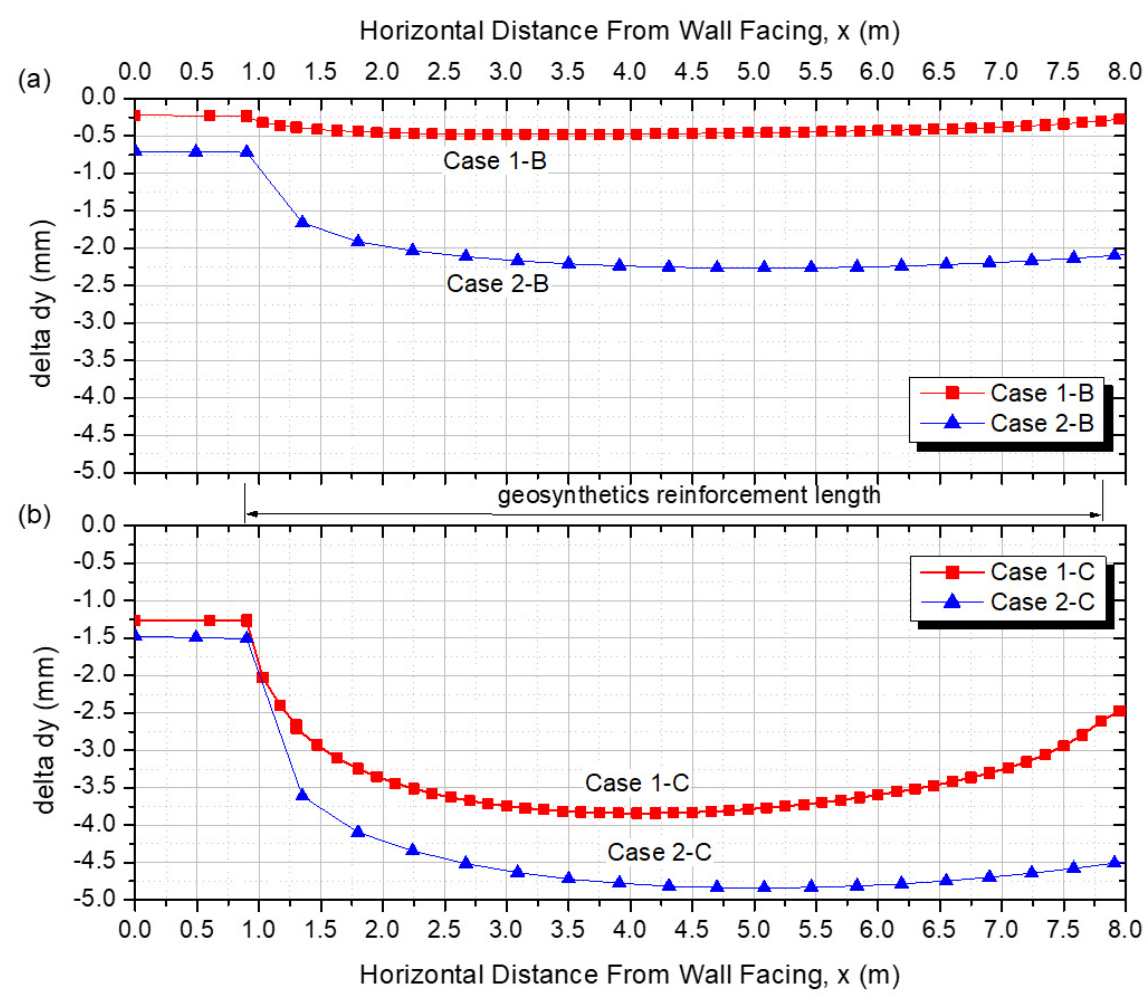

Figure 4. Vertical Displacement Increments at the top of Wall Abutment, $\Delta d y$ (mm), due to (a) General Traffic Loading (Case 1B-2B) and (b) Railway Loading (Case 1C-2C).

\section{Effects of Reinforcement Length}

According to FHWA [7], the reinforcement length is one of the factors that influenced the magnitude of wall deformation on the GRS wall. In this study, the GRS-IB models with different geosynthetics reinforcement lengths were analyzed to evaluate the effects of length-to-height ratio $(\mathrm{L} / \mathrm{H})$ of geosynthetics reinforcement on the deformation behavior of the integral bridge abutment. The GRS-IB models are simplified, having uniform reinforcement lengths throughout the entire height of the wall. The different length-to- 
height ratios of reinforcements used in the GRS model are $0.3 \mathrm{H}, 0.5 \mathrm{H}, 0.7 \mathrm{H}, 0.9 \mathrm{H}$, and $1.1 \mathrm{H}$ (where $\mathrm{H}$ is the height of the wall).

\subsection{Lateral Displacements at Wall Facing}

At the end of construction, the horizontal displacement ratios $(\mathrm{dx} / \mathrm{H})$ taken from the wall facing of the GRS-IB models with a different length-to-height ratio of reinforcements are shown in Figure 5. The figure shows three points at the wall facing: (1) at the base, (2) at the mid-height, and (3) at the top of the wall. The results show that maximum lateral displacements occurred at the top of the wall and the least at the base of the wall. It can be observed that the least reinforcement length, with the length-to-height ratio of $0.3 \mathrm{H}$, was obtained the highest $\mathrm{dx} / \mathrm{H}$. The $\mathrm{dx} / \mathrm{H}$ value gradually decreases as the reinforcement lengths increase from $0.3 \mathrm{H}$ to $1.1 \mathrm{H}$. Thus, the reinforcement length-to-height ratio of $1.1 \mathrm{H}$ obtained the least $\mathrm{dx} / \mathrm{H}$ at the end of construction. According to FHWA [7], one of the factors that affect the magnitude of lateral displacement at wall facing is the reinforcement length. Generally, the increase in the length-to-height ratio of reinforcements from $0.5 \mathrm{H}$ to $0.7 \mathrm{H}$ decreases the lateral displacements of the MSE wall by $50 \%$ (rough estimate) during the construction. In this study, the wall is modeled with $0.90 \mathrm{~m}$ thick FHR facing and GRS wall abutment; hence the increase in the length-to-height ratio of reinforcements from $0.5 \mathrm{H}$ to $0.7 \mathrm{H}$ decreases the lateral displacements at the wall by only $10 \%$. In addition, the increase on the length-to-height ratio of reinforcements from $0.3 \mathrm{H}$ to $1.1 \mathrm{H}$ decreases the maximum lateral displacements at the wall facing by $29 \%$. Note that the lateral displacements at the wall facing presented in the figure have been carried from the beginning of the construction and were not set to zero at the end of construction.

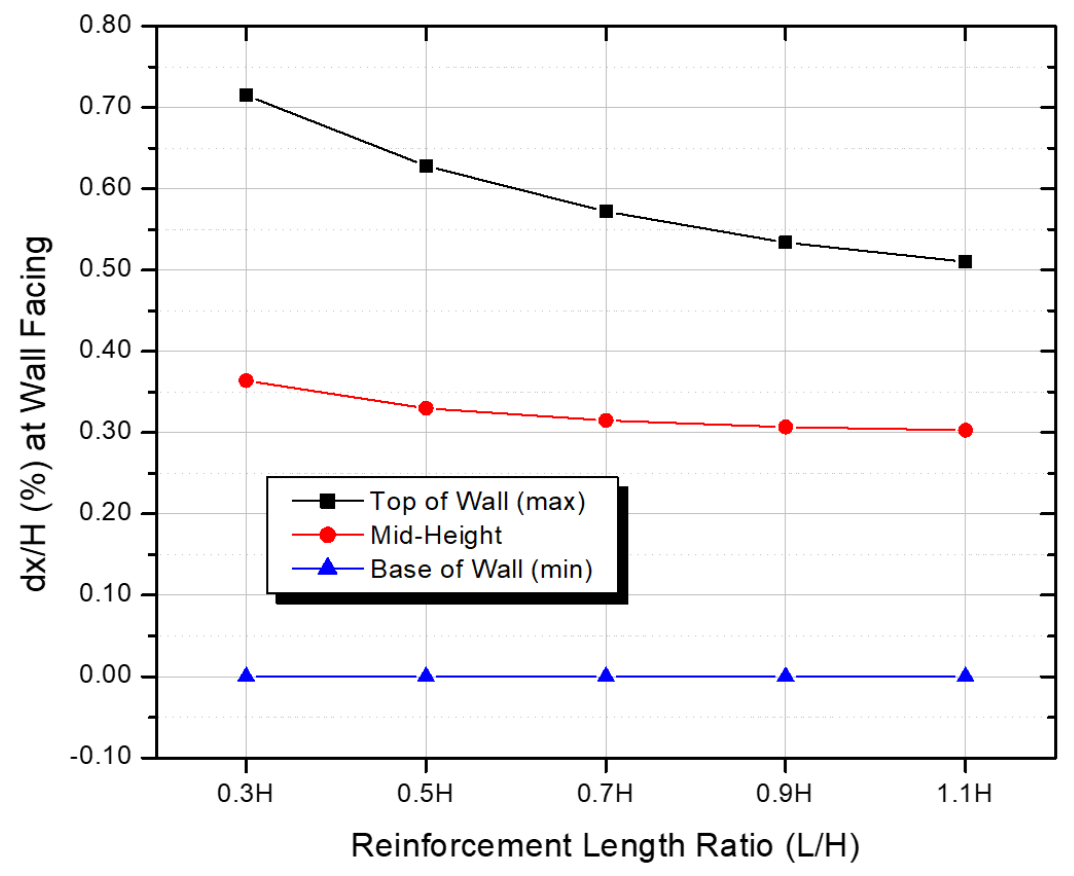

Figure 5. Lateral Displacement Ratio at Wall Facing.

The same behavior can be observed at the mid-height of the wall facing but with lesser values than those at the top of the wall. It can be observed that the least reinforcement length, with the length-to-height ratio of $0.3 \mathrm{H}$, obtained the highest $\mathrm{dx} / \mathrm{H}$. The $\mathrm{dx} / \mathrm{H}$ value gradually decreases as the reinforcement lengths increase from $0.3 \mathrm{H}$ to $1.1 \mathrm{H}$. Thus, the reinforcement length-to-height ratio of $1.1 \mathrm{H}$ obtained the least $\mathrm{dx} / \mathrm{H}$ at the end of construction. At mid-height, the increase in the length-to-height ratio of reinforcements from $0.5 \mathrm{H}$ to $0.7 \mathrm{H}$ decreases the lateral displacements at the wall by $5 \%$, which is equivalent to half of that at the top of the wall. In addition, the increase on the length-to-height ratio of 
reinforcements from $0.3 \mathrm{H}$ to $1.1 \mathrm{H}$ decreases the lateral displacements at mid-height of the wall facing by $17 \%$.

Moreover, it can be observed that the length-to-height ratio of reinforcements has no visible effects at the base of the wall. In this case, the increase on the length-to-height ratio of reinforcements from $0.3 \mathrm{H}$ to $1.1 \mathrm{H}$ decreases the lateral displacements at the base of the wall by less than $1 \%$. The total reinforcement length (L) required for internal stability is determined by adding the nonacting Rankine length $(\mathrm{Lr})$ and the embedment length (Le) beyond the potential failure surface $[7,34]$. The calculation suggests that the minimum required reinforcement length can be used at the base of the wall because the theoretically-calculated values of $\mathrm{Lr}$ and Le are minimal. Based on the internal stability calculation for extensible reinforcement like geosynthetics, the minimum requirement for the reinforcement length at the wall base is less than $0.3 \mathrm{H}$. Thus, in this case, the reinforcement length longer than $1.80 \mathrm{~m}$ may not have any remarkable effect on the lateral displacements at the wall facing. This explains why the length-to-height ratio of reinforcement from $0.3 \mathrm{H}$ to $1.1 \mathrm{H}$ has no visible effects at the base of the wall, as shown in Figure 5.

\subsection{Vertical Displacements at the Top of Wall Abutment}

In this study, the GRS-IB model is subjected to uniform loading on top, representing the equivalent bridge girder, and approach backfill total dead loads at the end of bridge construction. The GRS-IB model has a different length-to-height ratio of reinforcements starting from $0.3 \mathrm{H}, 0.5 \mathrm{H}, 0.7 \mathrm{H}, 0.9 \mathrm{H}$, to $1.1 \mathrm{H}$. FHWA [7] recommended a minimum reinforcement length of $0.7 \mathrm{H}$ for simple structures. Generally, for structures with other concentrated loads such as abutments, longer reinforcement lengths from $0.8 \mathrm{H}$ to $1.1 \mathrm{H}$ are recommended for stability. In this study, the vertical displacement ratio $(\mathrm{dy} / \mathrm{H})$ at the top of the wall with the different length-to-height ratios of reinforcements by the end of the construction is shown in Figure 6. The maximum vertical displacements occurred behind the wall facing due to the bridge girder total dead loads and because backfill soil has lesser stiffness than the FHR facing. Note that the vertical displacements of the wall have been carried from the beginning of the construction and were not set to zero at the end of construction. The results showed that the increase in the length-to-height ratio of reinforcements from $0.3 \mathrm{H}$ to $1.1 \mathrm{H}$ decreases the vertical displacements by $3 \%$ (at maximum) and $6 \%$ at the back (behind) and at the front of the wall facing, respectively. The effect of the reinforcement length on the wall vertical displacements is minimal compared with the effect on the wall lateral displacements, which agrees with Bilgin and Kim [35].

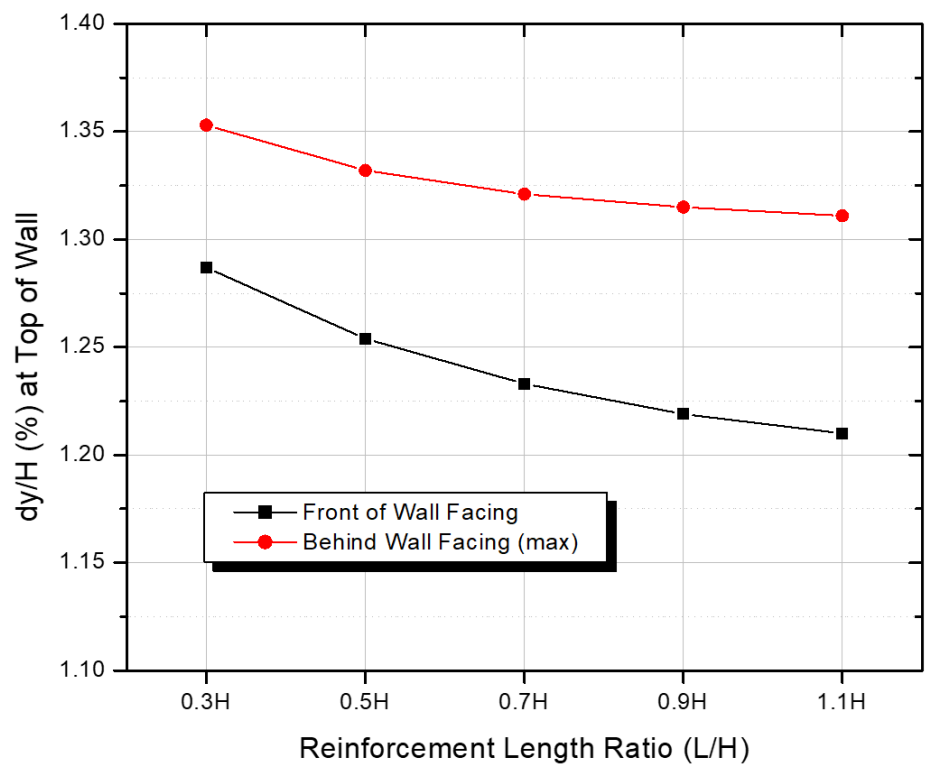

Figure 6. Vertical Displacement Ratio at the Top of Wall. 


\section{Conclusions}

In this study, the effects of geosynthetics reinforcement in the bridge abutment and the effects of geosynthetics reinforcement lengths on the deformation behavior of the integral bridge are presented. The main conclusions drawn from the series of numerical analyses using the Plaxis 2D program are as follows:

- The lateral displacement behavior at wall facing was influenced by the bridge abutment construction method, the use of geosynthetics reinforcement, and the reinforcement length.

- The GRS-IB model showed the least lateral displacements at the wall facing compared with those of the IB model without geosynthetics reinforcement.

- The presence of the reinforcements in the bridge abutment has reduced the vertical displacement increments by 4.7 times and 1.3 times (maximum) after the applied general traffic loads and railway loads, respectively.

- Increasing the length-to-height ratio of reinforcements from $0.3 \mathrm{H}$ to $1.1 \mathrm{H}$ decreased the maximum lateral displacements at the wall facing by $29 \%$ at the end of construction.

- The increase in the length-to-height ratio of reinforcements from $0.3 \mathrm{H}$ to $1.1 \mathrm{H}$ has no visible effects at the base of the wall.

- The increase in the length-to-height ratio of reinforcements from $0.3 \mathrm{H}$ to $1.1 \mathrm{H}$ decreases the vertical displacements by $3 \%$ (at maximum) and $6 \%$ at the back (behind) and at the front of the wall facing, respectively, at the end of construction.

- The effect of the reinforcement length on the wall vertical displacements is minimal compared to the effect on the wall lateral displacements.

The scope of the study is limited to the numerical analysis of the integral bridge with geosynthetic reinforced soil abutment and full height rigid facing (GRS-IB) in staged construction when one side of the bridge abutment is being modeled and simulated. Even though Plaxis 2D can simulate the actual behavior of the soil in the given condition, a field or laboratory experiment using the model is suggested for future study to validate the numerical analysis results.

Author Contributions: Conceptualization, M.-S.W. and C.P.L.; methodology, M.-S.W. and C.P.L.; software, C.P.L.; validation, M.-S.W. and C.P.L.; formal analysis, M.-S.W. and C.P.L.; investigation, C.P.L.; resources, M.-S.W.; data curation, C.P.L.; writing—original draft preparation, C.P.L.; writing—review and editing, M.-S.W. and C.P.L.; visualization, C.P.L.; supervision, M.-S.W.; project administration, M.-S.W.; funding acquisition, M.-S.W. All authors have read and agreed to the published version of the manuscript.

Funding: This research was supported by Basic Science Research Program through the National Research Foundation of Korea (NRF), funded by the Ministry of Education (NRF2021R1A6A1A0304518511).

Institutional Review Board Statement: Not applicable.

Informed Consent Statement: Not applicable.

Data Availability Statement: The data presented in this study are available on request from the corresponding author.

Conflicts of Interest: The authors declare no conflict of interest. The funders had no role in the design of the study; in the collection, analyses, or interpretation of data; in the writing of the manuscript, or in the decision to publish the results.

\section{References}

1. Tatsuoka, F.; Tateyama, M.; Koseki, J.; Yonezawa, T. Geosynthetic-reinforced soil structures for railways in Japan. Transp. Infrastruct. Geotechnol. 2014, 1, 3-53. [CrossRef]

2. Tatsuoka, F.; Tateyama, M.; Mohri, Y.; Matsushima, K. Remedial treatment of soil structures using geosynthetics-reinforcing technology. Geotext. Geomembr. 2007, 25, 204-220. [CrossRef]

3. Tatsuoka, F.; Tateyama, M.; Uchimura, T.; Koseki, J. Geosynthetic-reinforced soil retaining walls as important permanent structures. Geosynth. Int. 1997, 4, 81-136. [CrossRef] 
4. Tatsuoka, F.; Tateyama, M.; Koda, M.; Kojima, K.; Yonezawa, T.; Shindo, Y.; Amai, S. Recent research and practice of GRS integral bridges for railways in Japan. Jpn. Geotech. Soc. Spec. Publ. 2016, 2, 2307-2312. [CrossRef]

5. Adams, M.; Nicks, J.; Stabile, T.; Wu, J.; Schlatter, W.; Hartmann, J. Geosynthetic Reinforced Soil Integrated Bridge System, Synthesis Report (FHWA-HRT-11-027); Federal Highway Administration U.S. Department of Transportation: Washington, DC, USA, 2011.

6. Holtz, R.D. 46th Terzaghi lecture: Geosynthetic reinforced soil: From the experimental to the familiar. J. Geotech. Geoenviron. Eng. 2017, 143, 03117001-1-21. [CrossRef]

7. Berg, R.R.; Christopher, B.R.; Samtani, N.C. Design of Mechanically Stabilized Earth Walls and Reinforced Soil Slopes-Volume I (FHWA-NHI-10-024 FHWA GEC 011-Vol I); National Highway Institute, Federal Highway Administration, U.S. Department of Transportation: Washington, DC, USA, 2009.

8. Koerner, R.M.; Koerner, G.R. The importance of drainage control for geosynthetic reinforced mechanically stabilized earth walls. J. Geoeng. 2011, 6, 3-13.

9. Koerner, R.M.; Koerner, G.R. A data base, statistics and recommendations regarding 171 failed geosynthetic reinforced mechanically stabilized earth (MSE) walls. Geotext. Geomembr. 2013, 40, 20-27. [CrossRef]

10. Shin, E.C.; Cho, S.D.; Lee, K.W. Case study of reinforced earth wall failure during extreme rainfall. In Proceedings of the TC 302 Symposium: International Symposium on Backward Problems in Geotechnical Engineering and Monitoring of Geo-Construction, Osaka, Japan, 14-15 July 2011; pp. 146-153.

11. Das, B.M. Principles of Foundation Engineering, 7th ed.; Cengage Learning: Stamford, CT, USA, 2011.

12. Faizi, K.; Armaghani, D.J.; Kassim, A.; Lonbani, M. Evaluation of geotextiles on embankment displacement under seismic load. Electron. J. Geotech. Eng. 2013, 18, 439-449.

13. Won, M.S.; Langcuyan, C.P.; Gao, Y.C. A study on the utilization of clayey soil as embankment material through model bearing capacity tests. Appl. Sci. 2020, 10, 2315. [CrossRef]

14. Ziegler, M. Application of geogrid reinforced constructions: History, recent and future developments. Procedia Eng. 2017, 172, 42-51. [CrossRef]

15. Won, M.S. Effects of Reinforcement on Bearing Capacity of Loose Sand Foundation and Deformation Behavior of Buried Flexible Pipes. J. Test. Eval. 2010, 38, 232-241.

16. Armaghani, D.J.; Faizi, K.; Hajihassani, M.; Tonnizam, E.; Nazir, R. Effects of soil reinforcement on uplift resistance of buried pipeline. Measurement 2015, 64, 57-63. [CrossRef]

17. Won, M.S.; Langcuyan, C.P. Numerical analyses on the behavior of geosynthetic-reinforced soil: Integral bridge and integrated bridge system. Appl. Sci. 2021, 11, 8144. [CrossRef]

18. Abu-Farsakh, M.; Ardah, A.; Voyiadjis, G. 3D Finite element analysis of the geosynthetic reinforced soil-integrated bridge system (GRS-IBS) under different loading conditions. Transp. Geotech. 2018, 15, 70-83. [CrossRef]

19. Abu-Farsakh, M.; Ardah, A.; Voyiadjis, G. Numerical parametric study to evaluate the performance of a Geosynthetic Reinforced Soil-Integrated Bridge System (GRS-IBS) under service loading. Transp. Geotech. 2019, 20, 100238. [CrossRef]

20. Ardah, A.; Abu-Farsakh, M.; Voyiadjis, G. Numerical evaluation of the performance of a Geosynthetic Reinforced Soil-Integrated Bridge System (GRS-IBS) under different loading conditions. Geotext. Geomembr. 2017, 45, 558-569. [CrossRef]

21. Ardah, A.; Abu-Farsakh, M.; Voyiadjis, G. Numerical parametric study of geosynthetic reinforced soil integrated bridge system (GRS-IBS). Geotext. Geomembr. 2021, 49, 289-303. [CrossRef]

22. Zheng, Y.; Fox, P.J. Numerical investigation of the geosynthetic reinforced soil-integrated bridge system under static loading. J. Geotech. Geoenviron. Eng. 2017, 143, 04017008. [CrossRef]

23. Plaxis, B.V. Plaxis 2D Reference Manual; Plaxis B.V.: Delft, The Netherlands, 2018.

24. Plaxis, B.V. Plaxis 2D Tutorial Manual; Plaxis B.V.: Delft, The Netherlands, 2018.

25. Koda, M.; Nonaka, T.; Suga, M.; Kuriyama, R.; Tateyama, M.; Tatsuoka, F. A Series of Lateral Loading Tests on a Full-Scale Model of Geosynthetic-Reinforced Soil Integral Bridge. In Proceedings of the International Symposium on Design and Practice of Geosynthetic-Reinforced Soil Structures, Bologna, Italy, 11-16 October 2013; pp. 157-174.

26. Yazaki, S.; Tatsuoka, F.; Tateyama, M.; Koda, M.; Watanabe, K.; Duttine, A. Seismic design of GRS integral bridge. In Proceedings of the International Symposium on Design and Practice of Geosynthetic-Reinforced Soil Structures, Bologna, Italy, 11-16 October 2013; pp. 142-156.

27. Damians, I.P.; Bathurst, R.J.; Josa, A.; Lloret, A. Numerical analysis of an instrumented steel-reinforced soil wall. Int. J. Geomech. 2015, 15, 1-15. [CrossRef]

28. Damians, I.P.; Bathurst, R.J.; Lloret, A.; Josa, A. Vertical facing panel-joint gap analysis for steel-reinforced soil walls. Int. J. Geomech. 2016, 16, 04015103. [CrossRef]

29. Damians, I.P.; Bathurst, R.J.; Josa, A.; Lloret, A.; Albuquerque, P.J.R. Vertical facing loads in steel reinforced soil walls. J. Geotech. Geoenviron. Eng. 2013, 139, 1419-1432. [CrossRef]

30. Yu, Y.; Bathurst, R.J.; Allen, T.M.; Nelson, R. Physical and numerical modelling of a geogrid reinforced incremental concrete panel retaining wall. Can. Geotech. J. 2016, 53, 1883-1901. [CrossRef]

31. Yu, Y.; Bathurst, R.J. Influence of selection of soil and interface properties on numerical results of two soil geosynthetic interaction problems. Int. J. Geomech. 2017, 17, 04016136. [CrossRef]

32. Yu, Y.; Bathurst, R.J.; Miyata, Y. Numerical analysis of mechanically stabilized earth wall reinforced with steel strips. Soils Found. 2015, 55, 536-547. [CrossRef] 
33. Visone, C.; Santucci de Magistris, F. Some Aspects of Seismic Design Methods for Flexible Earth Retaining Structures. 2007. Available online: http:/ / www.reluis.it/doc/pdf/Pubblicazioni/vissao.pdf (accessed on 8 April 2021).

34. Murthy, V.N.S. Geotechnical Engineering: Principles and Practices of Soil Mechanics and Foundation Engineering; CRC Press: Boca Raton, FL, USA, 2002.

35. Bilgin, O.; Kim, H. Effect of soil properties and reinforcement length on mechanically stabilized earth wall deformations. Geotech. Spec. Publ. 2010, 384, 556-563. 